\title{
A Calculation Method of Bearing Capacity of Single Squeezed Branch Pile Based on Load Transfer Method
}

\author{
Li Liu $\mathbb{D}^{1},{ }^{1}$ Hong-wei Ma $\mathbb{D D}^{1,2}$ Xiao-li Yang $\mathbb{D}^{1},{ }^{1}$ Qing-rui He $\mathbb{D}^{1},{ }^{1}$ and Song Yuan $\mathbb{D}^{1}$ \\ ${ }^{1}$ School of Civil Engineering and Architecture, Anhui University of Science and Technology, Huainan 232000, China \\ ${ }^{2}$ State Key Laboratory of Mining Response and Disaster Prevention and Control in Deep Coal Mines, \\ Anhui University of Science and Technology, Huainan 232000, China
}

Correspondence should be addressed to Hong-wei Ma; hw_ma1984@126.com

Received 14 January 2022; Accepted 31 January 2022; Published 25 February 2022

Academic Editor: Yonghong Wang

Copyright (C) $2022 \mathrm{Li} \mathrm{Liu} \mathrm{et} \mathrm{al.} \mathrm{This} \mathrm{is} \mathrm{an} \mathrm{open} \mathrm{access} \mathrm{article} \mathrm{distributed} \mathrm{under} \mathrm{the} \mathrm{Creative} \mathrm{Commons} \mathrm{Attribution} \mathrm{License,} \mathrm{which}$ permits unrestricted use, distribution, and reproduction in any medium, provided the original work is properly cited.

\begin{abstract}
A calculation method of the bearing capacity of single squeezed branch pile is established based on the load transfer method. In the method, the hyperbolic model is used to describe the nonlinear load-displacement relationship of pile-soil interaction at the pile tip, the pile skin, and the squeezed branch, and the theoretical expression of six load transfer coefficients of squeezed branch pile is given. The correctness of the method is proved by a small-scale model test in homogeneous soil and a large-scale model test in stratified soil. The results show that the calculation based on the load transfer method is applicable to predict the ultimate load in engineering application.
\end{abstract}

\section{Introduction}

Foundation reinforcement is a conventional technique to improve foundation bearing capacity [1]. With the increasing complexity of geotechnical engineering problems, pile is widely used as building foundation or landslide protection structure [2]. However, the bearing capacity of pile foundation is more and more demanding, so the specialshaped pile, such as squeezed branch pile and screw pile, is used in engineering due to its characteristics of high bearing capacity and low settlement [3].

Squeezed branch pile is a special-shaped pile that makes some squeezed branches at the specific positions of a bored pile by rotary excavating and hydraulic squeeze expanding equipment. Wang [4] and $\mathrm{Xu}$ [5] believe that the squeezed branch pile is a multipoint support pile and has a larger bearing capacity and a smaller settlement than a bored pile with the same diameter. The squeezed branch pile can meet the requirement of heavy structure to the bearing capacity of foundation, and it has been widely used in pylons, highspeed and heavy-loaded railway, and other projects.

At present, there are many studies on the bearing capacity of the squeezed branch pile. Based on the static load test results, Qian [6] has analyzed the load transfer law of a squeezed branch pile and found that the pile is a friction end-bearing pile with multipoint support and is a variable section pile with obvious end-bearing property. Li [7], Zhang [8], and others completed some static load tests of practical engineering piles and found that all the squeezed branch piles in different sites showed the advantages of high bearing capacity and small settlement, and the contribution rate of squeezed branch resistance. However, the contribution of branch resistance to the bearing capacity varies significantly in different sites.

In order to obtain the general rule of the influence of squeezed branch on the bearing capacity of pile, Zhang $[9,10]$ has done a transparent soil model test based on transparent materials and particle image velocimetry (PIV) technique and found that the improvement of pile bearing capacity is due to the increase of the ranges of the deformation and displacement field of the soil around the pile and decrease of the maximums of deformation and displacement. Based on the model test, Zhang $[9,10]$ has carried out a numerical simulation study on the bearing capacity of the pile by using the finite element method (FEM) and analyzed the influence of the position, spacing, quantity, and diameter 
of squeezed branches on the pile bearing capacity and the soil displacement field. Moreover, Gao [11], Wang [12], Li [13] and so forth have also done the model test studied or numerical simulation research on squeezed branch pile.

In terms of the calculation of the squeezed branch pile, Gao [14] has established a function to predict the bearing capacity of the pile and has determined the parameters in the prediction function by analyzing a series of experimental results. The accuracy of the function in engineering problem prediction is proved by a case study. However, the prediction function cannot show the bearing mechanism of squeezed branch pile. Li [15] has presented a nonlinear method to analyze the bearing capacity of the squeezed branch pile based on the iterative algorithm of piecewise displacement and has studied the influence of four parameters, the friction angle of pile-soil interface, horizontal Earth pressure coefficient, the failure ratio of shaft resistance, and the failure angle of the soil under pile pit, on the bearing capacity of pile.

The studies mentioned above indicate that the penetration failure will not occur under the pile pit and the loadsettlement curves of squeezed branch piles are flat. Therefore, the hyperbolic function is an accurate function to describe the relationship between the resistances and the settlement of pile. Based on the load transfer method, a simple method to calculate the bearing capacity of squeezed branch piles is established in this paper, and the load transfer coefficient of the squeezed branch is regarded as a function of branch diameter. The reliability of the calculation method is proved by comparing the calculation results with the results of small-scale model test in homogeneous soil and large-scale test in layered field.

\section{Bearing Method of Single Branch Pile}

2.1. The Model of Single Branch Pile. A model of a single squeezed branch pile is established to analyze the stress mechanism of the pile as shown in Figure 1, where $d$ and $D$ are the shaft diameter and the squeezed branch diameter of the pile, respectively, and $\mathrm{L}_{2}$ and $\mathrm{L}_{1}$ are the pile lengths above and under the squeezed branch.

A settlement $s$ of the pile will occur due to the vertical load $P$ acted on the pile top, and it will cause the soil resistances consisting of shaft resistance $f$, pile tip resistance $R_{\mathrm{b}}$, and squeezed branch resistance $R_{\mathrm{p}}$. The vertical load is equal to the soil resistance in any case. Then the bearing capacity of the pile can be determined by the relationship between the settlement and the vertical load.

2.2. Calculation Method of Squeezed Branch Pile Based on the Load Transfer Method. The load transfer method, first proposed by Seed and Reese [16] in 1955, is becoming increasingly perfect in engineering application. Its basic idea is to solve the balance equation of the pile infinitesimal element according to the displacement coordination condition, based on the assumption that the pile body is discretized into a series of pile elements which are connected with the soil by nonlinear springs.
According to the load transfer method, the relationship between the pile tip resistance $R_{\mathrm{b}}$ and the pile tip settlement $s_{\mathrm{b}}$ satisfies the hyperbolic function, as well as the relationship between skin friction $\tau(\mathrm{z})$ and pile settlement $\mathrm{s}(\mathrm{z})$ at height $z$. The above relations can be expressed as

$$
\begin{gathered}
R_{b}=A \frac{s_{b}}{a_{s}+b_{s} s_{b}}, \\
\tau(z)=\frac{s(z)}{a_{f}+b_{f} s(z)} .
\end{gathered}
$$

In (1) and (2), $A=\pi \mathrm{d}^{2} / 4$ is the section area for a pile with diameter $d$, and $a_{\mathrm{s}}, b_{\mathrm{s}}$, and $a_{\mathrm{f}}, b_{\mathrm{f}}$ are the load transfer coefficients of the pile tip and the pile skin friction.

Since the squeezed branch pile's stress mechanism at the pile tip and the pile shaft is the same as the column pile's, (1) and (2) are applicable to the squeezed branch pile, although they are obtained from the analysis of the column pile.

According to the analysis of a large amount of test data, completed by Guo [17], the axial force of column pile is approximately linearly distributed along the pile axis. Therefore, if the pile under the squeezed branch with a tip settlement $s_{\mathrm{b}}$ is assumed to be rigid, the axial force of the section under the squeezed branch in the model shown in Figure 1(b) can be approximately expressed as

$$
\begin{aligned}
F_{N 1}^{\prime} & =R_{b}+f_{1}^{\prime} \\
& =R_{b}+\pi d L_{1} \frac{s_{b}}{a_{f 1}+b_{f 1} s_{b}} .
\end{aligned}
$$

In (3), $F_{N 1}^{\prime}$ is the approximate axial force of the section under the squeezed branch, $f_{1}^{\prime}$ is the approximate shaft resistance of the pile under the squeezed branch, and $a_{\mathrm{f} 1}$ and $b_{\mathrm{f} 1}$ are the load transfer coefficients of the pile skin on the pile tip.

Denote the elastic modulus of the pile as $E_{\mathrm{p}}$; then the compression of the pile under squeezed branch can be calculated by Hooke's law as follows:

$$
\Delta L_{1}=\left(R_{b}+F_{N 1}^{\prime}\right) \frac{L_{1}}{2 E_{P} A} .
$$

In order to correct the error of axial force caused by the above rigid pile assumptions, the axial force variation $\mathrm{d} F$ of infinitesimal element $\mathrm{d} z$ in the pile can be obtained as

$$
d F=\pi d \frac{s}{a_{f 0}+b_{f 0} s} d z .
$$

In equation (5), $s$ is the relative settlement of the infinitesimal element to a reference section, and $a_{\mathrm{f} 0}$ and $b_{\mathrm{fo}}$ are the load transfer coefficients of the pile skin on the reference section.

The elastic compression of the infinitesimal element can be expressed as

$$
d s=\frac{F}{E_{p} A} d z .
$$




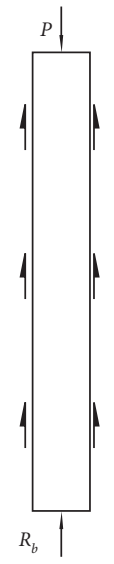

(a)

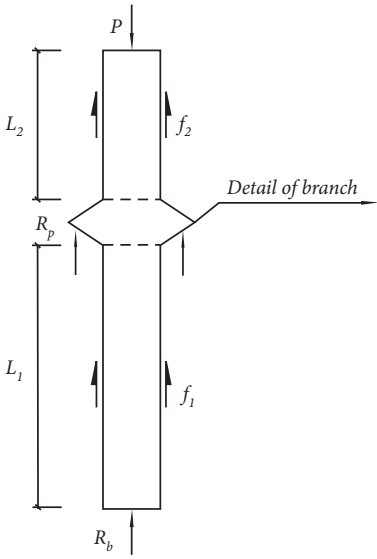

(b)

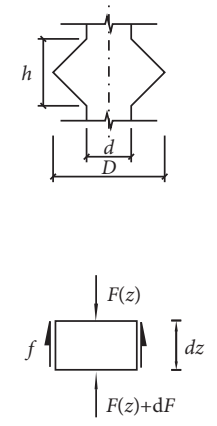

(c)

Figure 1: The model.

According to (5) and (6), the differential equation of axial force can be calculated by

$$
F d F=\pi d E_{p} A \frac{s}{a_{f 0}+b_{f 0} s} d s .
$$

By using the initial conditions $F_{\mathrm{N}}=0$ and $s=0$, the integral of (7) is

$$
F=\sqrt{\frac{2 \pi d E_{P} A}{b_{f 0}}\left[s-\frac{a_{f 0}}{b_{f 0}} \ln \left(1+\frac{b_{f 0}}{a_{f 0}} s\right)\right]} .
$$

In the model shown in Figure 1(b), if the pile tip is regarded as the reference section, then $\Delta L_{1}$ in (4) is the relative displacement of the section under the squeezed branch to the pile tip, and the shaft resistance of the pile under the squeezed branch, denoted as $f_{1}$, equals the relative axial force. Replace $F, s$, and $a_{\mathrm{f} 0}$ and $b_{\mathrm{f} 0}$ in (8) with $f_{1}, \Delta L_{1}$, and the load transfer coefficients of the pile skin on the pile tip $a_{\mathrm{f} 1}$ and $b_{\mathrm{f} 1}$, and the shaft resistance of the pile under the squeezed branch can be expressed as

$$
f_{1}=\sqrt{\frac{2 \pi d E_{P} A}{b_{f 1}}\left[\Delta L_{1}-\frac{a_{f 1}}{b_{f 1}} \ln \left(1+\frac{b_{f 1}}{a_{f 1}} \Delta L_{1}\right)\right]} .
$$

Therefore, the corrected axial force of the section under the squeezed branch can be calculated by

$$
F_{N 1}=R_{b}+f_{1} .
$$

The settlement of the squeezed branch $s_{\mathrm{p}}$, which is equal to the settlement of the section under the squeezed branch, can be written as

$$
s_{p}=s_{b}+\Delta L_{1} .
$$

The squeezed branch has an interaction mechanism with the soil similar to the pile tip, so the hyperbolic function can be used to describe the relationship between resistance and settlement of the squeezed branch. By referring to (1), the relationship between $R_{\mathrm{p}}$ and $s_{\mathrm{p}}$ can be written as

$$
R_{p}=A_{p} \frac{s_{p}}{a_{p}+b_{p} s_{p}} .
$$

In (12), $A_{\mathrm{p}}=A\left(\alpha^{2}-1\right)$ is the horizontally projected area of the squeezed branch, and $\alpha=D / \mathrm{d}$ is the ratio of the squeezed branch diameter to the shaft diameter; $a_{\mathrm{p}}$ and $b_{\mathrm{p}}$ are the load transfer coefficients of the squeezed branch associated with $\alpha$ and the dip angle of squeezed branch lower surface.

Therefore, the axial force of the section over the squeezed branch is calculated by

$$
F_{N 2}=F_{N 1}+R_{p} .
$$

By referring to the calculation method of $f_{1}$ and ignoring the slight compression of the squeezed branch, the compression and shaft resistance of the pile over the squeezed branch, denoted as $\Delta \mathrm{L}_{2}$ and $f_{2}$, can be written as follows

$$
\begin{aligned}
\Delta L_{2} & =\left(2 F_{N 2}+\pi d L_{2} \frac{s_{p}}{a_{f 2}+b_{f 2} s_{p}}\right) \frac{L_{2}}{2 E_{P} A}, \\
f_{2} & =\sqrt{\frac{2 \pi d E_{P} A}{b_{f 2}}\left[\Delta L_{2}-\frac{a_{f 2}}{b_{f 2}} \ln \left(1+\frac{b_{f 2}}{a_{f 2}} \Delta L_{2}\right)\right]} .
\end{aligned}
$$

In (14) and (15), $a_{\mathrm{f} 2}$ and $b_{\mathrm{f} 2}$ are the load transfer coefficients of the pile skin on the squeezed branch upper surface.

Now all the resistances and compressions of the single squeezed branch pile in Figure 1 caused by pile tip settlement $s_{\mathrm{b}}$ have been calculated. According to the static equilibrium and displacement coordination conditions of the pile, the vertical load and the settlement of the pile top in Figure 1, denoted as $P$ and $s$, can be calculated by

$$
\begin{aligned}
s & =s_{b}+\Delta L_{1}+\Delta L_{2}, \\
P & =R_{b}+f_{1}+R_{p}+f_{2} .
\end{aligned}
$$


Obviously, for any pile tip settlement, the vertical load and settlement of the pile top are easy to obtain. The $P$-s (load-settlement) curve, to reflect the ultimate bearing capacity of the squeezed branch pile, can be obtained by inputting a series of pile end settlements.

For a special problem of a squeezed branch pile in layered soil, it can be solved according to the following method: the model can be divided by the soil boundary, and set a hypothetical squeezed branch with diameter $D=d$ on the soil boundary.

\subsection{Calculation Method of Ultimate Bearing Capacity of the} Pile. The ultimate bearing capacity of piles can be determined with reference to the design specification for cast-inplace piles with expanded branches and bells by 3-way extruding arms [18] (JGJ171-2009). The pile tip load $P$ and settlement $s$ are obtained in the calculation process, and the judgement method is determined by the settlement increment $\triangle s_{1}$ of pile top load from 9P/11.to $10 \mathrm{P} / 11$ and the settlement increment $\triangle s_{2}$ of pile top load from $10 \mathrm{P} / 11$ to $\mathrm{P}$. Because the $P$-s curve of squeezed branch pile has slow deformation, there is no obvious steep drop section in it. If the calculation condition $\triangle s_{2}>2 \triangle s_{1}$ is met, the calculation ends, and the ultimate bearing capacity of the pile is determined to be $10 \mathrm{P} / 11$.

\subsection{The Load Transfer Coefficients}

2.4.1. $a_{s}$ and $b_{s}$. Based on the principle of elasticity, the relationship between the resistance and settlement of pile tip given by Randolph [19] is as follows:

$$
s_{b}=\frac{R_{b}\left(1-\mu_{b}\right)}{2 G_{b} d} .
$$

In (17), $G_{\mathrm{b}}$ and $\mu_{\mathrm{b}}$ are the shear modulus and Poisson's ratio of the soil at the pile end, respectively.

Actually, the soil under the pile tip is in the elastic stress-strain state in the initial loading stage of the pile, and the effect of the nonlinear parameter $b_{s}$ in (1) on the relationship between $R_{\mathrm{b}}$ and $s_{\mathrm{b}}$ can be ignored. By substituting (17) into (1) and defining $b_{\mathrm{s}}=0$, the expression of $a_{\mathrm{s}}$ can be written as

$$
a_{s}=\frac{\pi d}{8 G_{b}}\left(1-\mu_{b}\right) .
$$

According to the cavity expansion method put forward by Janbu [20], the compacting core of the soil under the pile tip gradually expands as the load increases during the pile foundation loading, and the ultimate pile tip resistance $R_{b u}$ can be expressed as

$$
R_{b u}=A\left(c_{b} N_{c b}+q_{b} N_{q b}\right) .
$$

In (19), $c_{b}$ is the cohesion of the soil under pile tip, $\mathrm{N}_{\mathrm{cb}}$ and $\mathrm{N}_{\mathrm{qb}}$ are the dimensionless bearing capacity coefficients reflecting the influence of cohesion and lateral pressure of the soil under pile tip, and $q_{\mathrm{b}}$ is the average of the effective vertical Earth pressure at the side of pile tip. Denoting the weighted value of unit weight, the effective friction angle, and the failure angle of the soil as $\gamma, \varphi$, and $\psi, \mathrm{N}_{\mathrm{cb}}, \mathrm{N}_{\mathrm{qb}}$, and $q_{\mathrm{b}}$ can be written as

$$
\begin{aligned}
N_{c b} & =\left(N_{q b}-1\right) \cot \varphi, \\
N_{q b} & =(\tan \varphi+\sec \varphi)^{2} e^{2 \psi \tan \varphi}, \\
q_{b} & =\left(1-\frac{2}{3} \sin \varphi\right) \gamma_{b} L .
\end{aligned}
$$

Under the ultimate loading state, the effect of the linear parameter $a_{\mathrm{s}}$ in (1) on the relationship between $R_{\mathrm{b}}$ and $s_{\mathrm{b}}$ can be ignored; by substituting (19) into (1) and defining $a_{\mathrm{s}}=0$, the expression of $b_{\mathrm{s}}$ can be written as

$$
\begin{aligned}
b_{s} & =\frac{A}{R_{b u}} \\
& =\frac{1}{c_{b} N_{c b}+q_{b} N_{q b}} .
\end{aligned}
$$

2.4.2. $a_{f}$ and $b_{f}$. The relationship between the skin friction $\tau$ and the settlement $s$ of the pile given by Randolph [21] can be written as

$$
\tau=\frac{2 G_{s}}{d \ln \left(2 r_{m} / d\right)} s .
$$

In (22), $G_{\mathrm{s}}$ is the shear modulus of the soil around the computed section, $r_{\mathrm{m}}$ is the influence radius of the pile and can be calculated by $r_{\mathrm{m}}=2.5 \mathrm{~L} \rho_{\mathrm{m}}\left(1-\mu_{\mathrm{s}}\right), \rho_{\mathrm{m}}$ is the ratio of the weighted value to the maximum of the shear modulus of soil around the pile, and $\mu_{\mathrm{s}}$ is the weighted average of Poisson's ratio of the soil around the pile.

By using the same method used to determine $a_{\mathrm{s}}$, in the initial loading stage of the pile, by substituting (22) into (2) and defining $b_{\mathrm{f}}=0$, the expression of $a_{\mathrm{f}}$ can be written as

$$
a_{f}=\frac{d}{2 G_{s}} \ln \left(\frac{2 r_{m}}{d}\right) .
$$

The formula of the pile ultimate skin friction $\tau_{\mathrm{u}}$ given by Clough [21] is

$$
\tau_{u}=\frac{k \sigma_{v} \tan \delta}{R_{f}} .
$$

In (24), the coefficient of lateral Earth pressure $k$ and the friction angle of pile-soil interface $\delta$ can be evaluated by Table 1 and Table 2 , the vertical stress in soil $\sigma_{v}$ can be calculated by unit weight of soil and burial depth, and the failure ratio of shaft resistance $R_{\mathrm{f}}$ is 0.80 to 0.95 .

Similarly, under the ultimate loading state, by substituting (24) into (2) and defining $a_{\mathrm{f}}=0$, the expression of $b_{\mathrm{f}}$ can be written as

$$
b_{f}=\frac{1}{\tau_{u}}=\frac{R_{f}}{k \sigma_{v} \tan \delta} .
$$


TABLE 1: Suggested value of the lateral Earth pressure coefficient $k$.

\begin{tabular}{lcc}
\hline Working conditions & $k /(1-\sin \varphi)$ & Data provider \\
\hline Steel pipe piles, concrete piles, or H-shaped steel piles with smooth surface and a small settlement & 0.7 to 1.2 & Kulhawy [22] \\
Driven steel piles in alluvial deposit or fully weathered granite & 1.2 to 1.5 & Yang [23] \\
\hline
\end{tabular}

TABLE 2: Suggested value of the friction angle of pile-soil interface $\delta$.

\begin{tabular}{lcc}
\hline Working conditions & $\delta\left(^{\circ}\right)$ & Data provider \\
\hline Pipe piles in dense sand & 29.4 & Neill [24] \\
Concrete piles in muddy soil or clay & 21.3 to 31.6 & Liu [25] \\
Driven piles in sand & 28.0 to 30.0 & Jardine [26] \\
\hline
\end{tabular}

2.4.3. $a_{p}$ and $b_{p}$. The ratio of squeezed branch diameter and pile diameter influences the interaction of branch soil. To simplify the calculations, the load transfer coefficients of the squeezed branch resistance and pile tip resistance have the same form. It is assumed that the branch resistance of the squeezed branch pile is the quotient of the end resistance and the correction function under the same settlement; the expression of $R_{\mathrm{p}}$ can be written as

$$
R_{p}=A\left(\alpha^{2}-1\right) \frac{s_{p}}{a_{p}+b_{p} s_{p}} .
$$

Then $a_{\mathrm{p}}$ and $b_{\mathrm{p}}$ can be written as

$$
\begin{aligned}
& a_{p}=\xi(\alpha)\left(\alpha^{2}-1\right) \frac{\pi d}{8 G_{p}}\left(1-\mu_{p}\right), \\
& b_{p}=\xi(\alpha)\left(\alpha^{2}-1\right) \frac{1}{c_{p} N_{c p}+q_{p} N_{q p}} .
\end{aligned}
$$

In (27) and (28), $\xi(\alpha)$ is the correction coefficient of branch resistance. Ma Hong-wei [27] modified the load transfer parameters of the end resistance of the expanded body by the least square method. The empirical equation fitted to it can be written as

$$
\xi(\alpha)=0.36 \alpha^{2}-2.36 \alpha+4.20 \text {. }
$$

The shear modulus, Poisson's ratio, and the cohesion of the soil under the branch tip are $G_{\mathrm{p}}, \mu_{\mathrm{p}}$, and $c_{\mathrm{p}} ; \mathrm{N}_{\mathrm{cp}}$ and $\mathrm{N}_{\mathrm{qp}}$ are the dimensionless bearing capacity coefficients reflecting the influence of cohesion and lateral pressure of the soil under the branch tip; $q_{\mathrm{p}}$ is the average of the effective vertical Earth pressure at the side of the branch tip. Denoting the weighted value of unit weight, the effective friction angle, and the failure angle of the soil at the branch tip as $\gamma_{\mathrm{p}}, \varphi_{\mathrm{p}}$, and $\psi_{\mathrm{p}}, \mathrm{N}_{\mathrm{cp}}, \mathrm{N}_{\mathrm{qp}}$, and $\mathrm{qp}$ can be written as

$$
\begin{aligned}
N_{c p} & =\left(N_{q p}-1\right) \cot \varphi, \\
N_{q p} & =(\tan \varphi+\sec \varphi)^{2} e^{2 \psi \tan \varphi}, \\
q_{p} & =\left(1-\frac{2}{3} \sin \varphi\right) \gamma_{p} L .
\end{aligned}
$$

\section{Model Test Validation and Discussion}

3.1. Verification by a Small-Scale Model Test in Homogeneous Soil. Six model piles with different branch diameters buried in the same homogeneous soil have been loaded.
In the model pile tests, the pile diameter is $20 \mathrm{~mm}$, the length of pile is $500 \mathrm{~mm}$, and the buried depth of squeezed branch is $150 \mathrm{~mm}$. The model piles are made from aluminum alloy tubes, the thickness of the tube is $3 \mathrm{~mm}$, and the elastic modulus of pile material is $63.1 \mathrm{GPa}$. The short side board of the model box is made of perspex, and the long side and bottom board are made of steel boards. The load device and model pile are shown in Figure 2.

In Figure 2(a), the loading beam is used to load on the pile top using the lever principle, and its weight can be balanced by the balance beam before loading.

According to Bai $[28,29]$, the interaction mechanism of soil under different temperature and water content is different, which changes the stress transfer mechanism of soil around the pile. Therefore, in order to ensure that the parameters of the test sand are the same in repeated tests, the test was carried out in a room with stable temperature and humidity. Before loading, in order to make the soil around the pile stable, the test was carried out after standing for $24 \mathrm{~h}$ $[30,31]$.

Based on geotechnical tests, Poisson's ratio of the soil is 0.25 and the elastic modulus is $21.2 \mathrm{MPa}$.

The load mode of test adopted a lever loading system which can balance the weight of load beam, the settlement of pile top was measured by dial gauge, and a high-speed static strain gauge (YE2539) was used to measure the strain to obtain the axial force of the pile.

The model piles are buried in the soil during the filling process, as was done in Yuan's [32] study. The parameters of six model piles are shown in Table 3.

The calculation results and model test results of $P-s$ (load-settlement) curves of six model piles with different branch diameters are shown in Figure 3. The relative error analysis of the calculation results and model test results is shown in Table 4.

In Figure 3, according to the results of the $P$-s curves of 6 piles calculated by method, it is found that they almost coincide with the measured curve of the test pile, which indicates that the calculation results are significantly consistent with the test results.

According to Table 4, the maximum relative error between the calculation and model test results of each pile is $18.01 \%$. After loading the pile top bearing capacity to $1200 \mathrm{~N}$, the relative error of settlement is stable within $10 \%$. In engineering applications, relative error results like these can be accepted, especially for type of discrete large geotechnical applications.

The comparison of theoretical result and test pile result on the composition of bearing capacity of S2 pile is shown in Figure 4. The relative error analysis results of the calculation result and test result are shown in Table 5. 


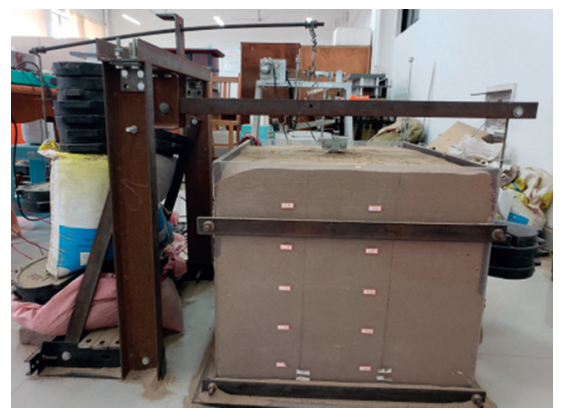

(a)

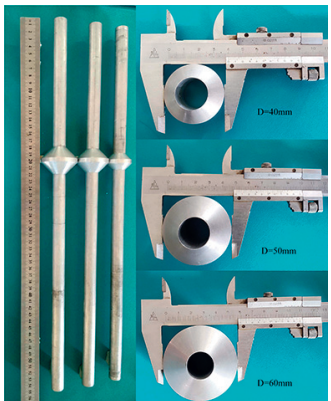

(b)

Figure 2: Load device and model pile: (a) load device; (b) reality of the model pile.

TABle 3: Model pile parameters.

\begin{tabular}{lccccc}
\hline No. & $\alpha$ & $\mathrm{D}(\mathrm{mm})$ & $\mathrm{H}(\mathrm{mm})$ & $\mathrm{L}_{1}(\mathrm{~mm})$ & $\mathrm{L}_{2}(\mathrm{~mm})$ \\
\hline S1 & 1.75 & 35 & 20 & 340.0 & 140.0 \\
S2 & 2.00 & 40 & 25 & 337.5 & 137.5 \\
S3 & 2.25 & 45 & 30 & 335.0 & 135.0 \\
S4 & 2.50 & 50 & 34 & 332.5 & 132.5 \\
S5 & 2.75 & 55 & 40 & 330.0 & 130.0 \\
S6 & 3.00 & 60 & 45 & 327.5 & 127.5 \\
\hline
\end{tabular}

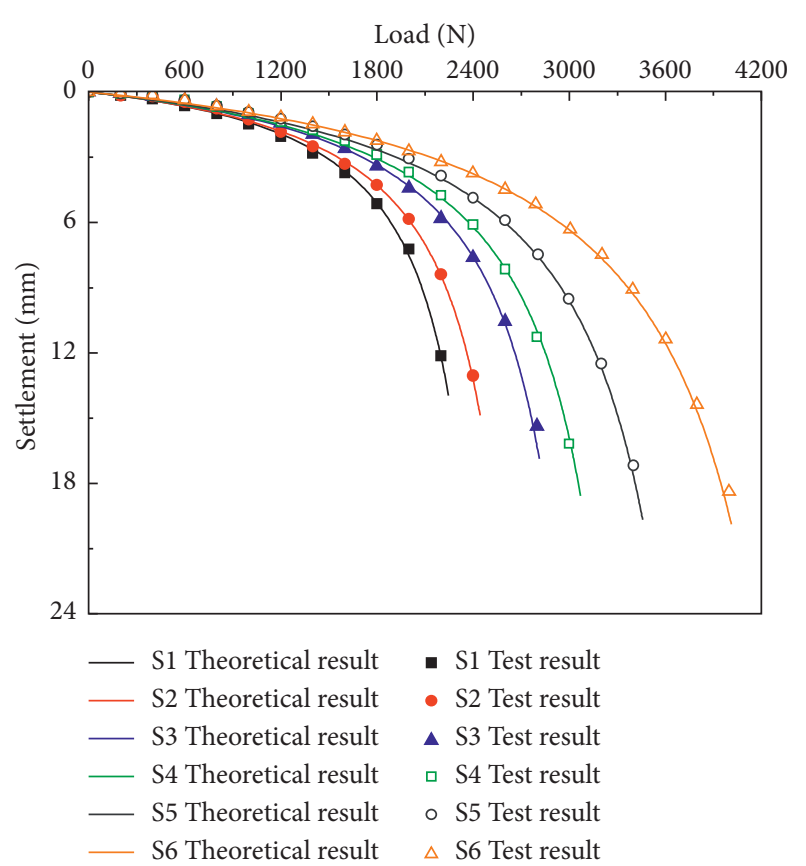

Figure 3: Comparison of $P$-s curves between test piles and method result.

In Figure 4, the calculation results almost coincide with the test pile results for the pile tip resistance, squeezed branch resistance, and pile skin resistance of S2 pile. The maximum relative errors of pile tip resistance, squeezed branch resistance, and pile skin resistance are 5.78\%, $2.72 \%$, and $6.45 \%$, respectively, which indicate that the calculation
TABLE 4: Relative error analysis of the settlement above test piles (\%).

\begin{tabular}{lcccccc}
\hline Load $(\mathrm{N})$ & S1 & S2 & S3 & S4 & S5 & S6 \\
\hline 800 & 0.29 & 14.95 & 11.29 & 18.01 & 17.89 & 11.76 \\
1000 & 4.22 & 6.12 & 16.14 & 17.26 & 14.67 & 4.54 \\
1200 & 5.09 & 0.21 & 8.83 & 10.79 & 10.36 & 4.32 \\
1400 & 6.42 & 3.13 & 4.37 & 10.84 & 10.48 & 2.55 \\
1600 & 1.91 & 4.29 & 0.67 & 8.98 & 10.24 & 0.20 \\
1800 & 0.02 & 0.26 & 1.66 & 6.18 & 9.28 & 0.26 \\
2000 & 4.49 & 0.53 & 1.94 & 4.25 & 5.86 & 2.25 \\
2200 & - & 0.88 & 2.72 & 2.35 & 2.65 & 1.70 \\
2400 & - & - & 0.58 & 1.23 & 0.03 & 0.76 \\
2600 & - & - & - & 0.81 & 1.26 & 0.54 \\
2800 & - & - & - & 2.65 & 1.32 & 2.00 \\
3000 & - & - & - & - & 0.67 & 0.92 \\
3200 & - & - & - & - & - & 2.41 \\
3400 & - & - & - & - & - & 2.16 \\
3600 & - & - & - & - & - & 1.76 \\
\hline & & & & & &
\end{tabular}

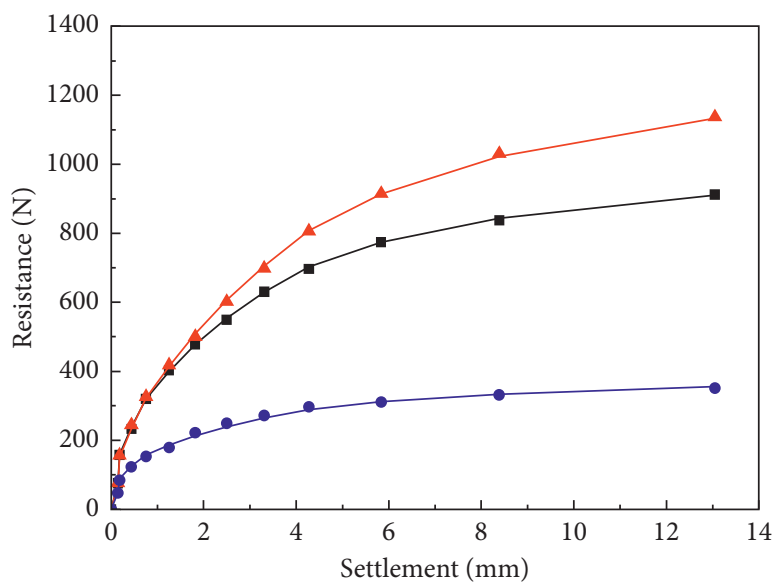

- Test pile tip resistance

- Test branch resistance

- Test pile skin resistance

— Theoretical pile tip resistance

— Theoretical branch resistance

_ Theoretical pile skin resistance

FIGURE 4: Bearing capacity composition analysis of S2 pile. 
TABLE 5: Relative error analysis of pile bearing capacity composition (\%).

\begin{tabular}{lccc}
\hline Load $(\mathrm{N})$ & Pile tip resistance & Branch resistance & Pile skin resistance \\
\hline 200 & 5.78 & 1.87 & 6.45 \\
400 & 3.11 & 0.22 & 5.33 \\
600 & 3.77 & 2.72 & 2.34 \\
800 & 1.39 & 0.04 & 2.89 \\
1000 & 0.89 & 0.82 & 3.93 \\
1200 & 1.85 & 0.06 & 4.03 \\
1400 & 0.74 & 0.96 & 3.90 \\
1600 & 1.03 & 0.06 & 2.50 \\
1800 & 0.30 & 0.81 & 2.73 \\
2000 & 0.09 & 0.01 & 0.27 \\
2200 & 0.80 & 0.76 & 0.58 \\
2400 & 0.31 & 0.11 & 1.27 \\
\hline
\end{tabular}

results are significantly consistent with the model test results, proving that the calculation result can be accepted.

\subsection{Validation by the Large-Scale Field Test in Layered Soil}

3.2.1. The Test Data. The P-s relationship of a squeezed branch pile in Beijing is given by Tang [33] through largescale field test.

In the large-scale field test, the pile length is $2000 \mathrm{~mm}$, the pile diameter is $150 \mathrm{~mm}$, and the branch diameter of pile is $300 \mathrm{~mm}$. The branch is located in dense clay with buried depth of $-1 \mathrm{~m}$. The squeezed branch pile is made of C30 concrete with a $\Phi 14$ steel bar.

In the large-scale field test, there was failure in the single squeezed branch pile after loading 8 stages. According to the "Technical Specification for Building Pile Test" in China, the ultimate bearing capacity of the pile is $80 \mathrm{kN}$. The test data results are shown in Table 6.

3.2.2. Verification of the Accuracy of Calculation Results. Based on the relationship between elastic modulus and compression modulus of soil, proposed by Yang [34] for calculation, the elastic modulus of clay and sandy silt in Tang's test is $32.9 \mathrm{MPa}$ and $245 \mathrm{MPa}$. Poisson's ratios of clay and sandy silt are taken as 0.25 and 0.30 , horizontal soil pressure coefficient $k$ is $1.2 k_{0}$, break ratio $R_{\mathrm{f}}$ is 0.95 , and pile tip failure angle $\psi$ is $90^{\circ}$.

According to the above field large-scale test parameters, using this article's method to calculate, Tang [33] used Geddes solution and stratified summation method to calculate the settlement of single squeezed branch pile and Tang's field test results all of these comparisons are shown in Figure 5.

According to the curve comparison analysis shown in Figure 5, the deviation between calculated and field test results is small for load-settlement curves. In the early loading stage, the field test settlement is higher than the calculation; it may be due to the fact that the test pile is made by drilling and reaming on the spot, which leads to the sediment thickness at the bottom of the pile being considerably incomplete. Thus, the settlement in the field test is higher than that in the calculated result. With the load
TABLE 6: Data of the large-scale model test [33].

\begin{tabular}{lccccccccc}
\hline $\begin{array}{l}\text { Loading } \\
\text { stage }\end{array}$ & 0 & 1 & 2 & 3 & 4 & 5 & 6 & 7 & 8 \\
\hline $\begin{array}{l}\text { Load } P(\mathrm{kN}) \\
\begin{array}{l}\text { Settlement } s \\
(\mathrm{~mm})\end{array}\end{array}$ & 0.0 & 20.0 & 30.0 & 40.0 & 50.0 & 60.0 & 70.0 & 80.0 & 90.0 \\
\hline
\end{tabular}

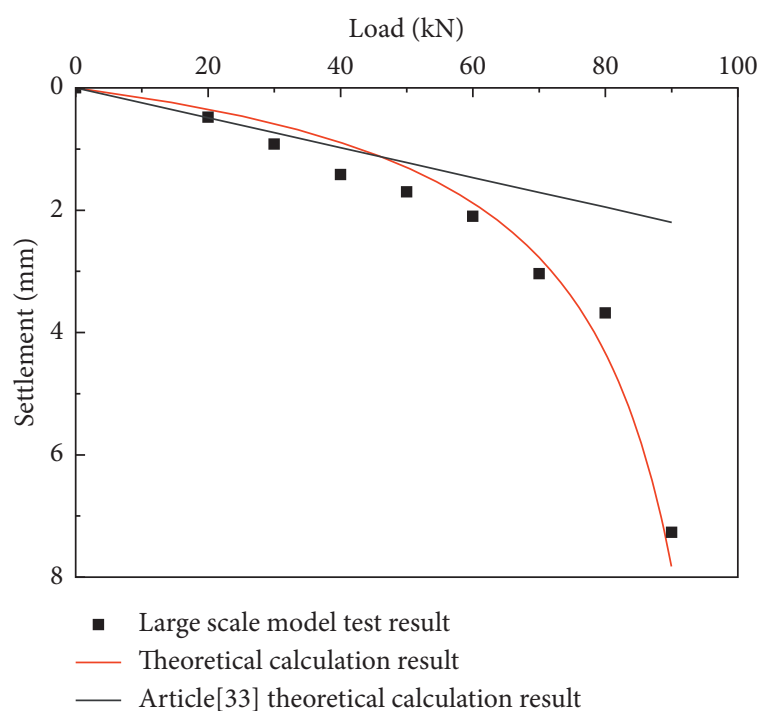

Figure 5: Comparison of the pile curve.

increase of pile top, there is a trend of decrease between the test result and the absolute error of calculation.

Geddes solution and stratified summation method were used by Tang [33] to calculate the settlement results for a single squeezed branch pile, which are far from the field test results, and it is indicated that the load transfer method is superior to the Geddes solution and stratified summation method.

Through the error analysis of Table 7, the absolute error between the field test pile and the calculation results is not more than $\pm 1 \mathrm{~mm}$ during the whole loading period. Table 7 shows that the pile top load $P$ is obtained by assuming that the pile tip settlement increment $\Delta s$ is $0.01 \mathrm{~mm}$ in field test. Using the calculation method of ultimate bearing capacity to 
TABLE 7: Analysis of the field test and theoretical results.

\begin{tabular}{|c|c|c|c|c|c|c|c|c|}
\hline Load $(\mathrm{kN})$ & 20.00 & 30.00 & 40.00 & 50.00 & 60.00 & 70.00 & 80.00 & 90.00 \\
\hline Absolute error (mm) & 0.307 & 0.525 & 0.387 & 0.179 & 0.265 & 0.706 & 0.218 & 0.112 \\
\hline Ultimate bearing capacity $(\mathrm{kN})$ & - & - & - & - & - & - & 81.17 & - \\
\hline Relative error (\%) & - & - & - & - & - & - & 1.46 & - \\
\hline
\end{tabular}

predict the ultimate load of the test pile, the relative error result of the predicted and field test ultimate load is $1.46 \%$, which indicates that this calculation method is applicable to predict the ultimate load in engineering application.

\section{Conclusions}

(1) A method is established to calculate the bearing capacity of a single squeezed branch pile based on the load transfer method. In the method, the hyperbolic function is used to describe the relationship between the settlement and resistance caused by squeezed branch, pile tip, and pile shaft to reflect the nonlinear characteristics of the interaction between pile and soil. The $P$-s (load-settlement) curve of squeezed branch pile can be calculated by different pile tip settlement by using the method, and the ultimate bearing capacity of the pile can be obtained by $P$-s curve. The method is also applicable to piles in layered soil.

(2) From the model test, the bearing capacity of the squeezed branch pile increases continuously with the increase of the branch diameter, and the increasing rate continues to increase. At the same time, it can be seen from the bearing capacity of each part of the pile body that the bearing capacity of the squeezed branch pile is mainly borne by the branch and the pile end, while the pile side friction bears less load.

(3) The correctness of the squeezed branch pile method is proved by a small-scale model test in homogeneous soil and a large-scale model test in layered soil. Through the prediction of the ultimate bearing capacity for smalland large-scale model tests, it is found that the error between the model pile tests and the calculation results of each pile is small, and the results show that the calculation of the single squeezed branch pile based on load transfer method is reliable in the prediction of the ultimate load in practical engineering.

\section{Data Availability}

The datasets generated during the current study are available from the corresponding author upon reasonable request.

\section{Conflicts of Interest}

The authors declare that there are no conflicts of interest regarding the publication of this paper.

\section{Acknowledgments}

The authors sincerely thank the School of Civil Engineering and Architecture, State Key Laboratory of Mining Response and Disaster Prevention and Control in Deep Coal Mines in Anhui University of Science and Technology, for providing the experiment conditions. This work was supported by the National Natural Science Foundation of China (51408006).

\section{References}

[1] B. X. Yuan, Z. H. Li, Y. M. Chen et al., "Mechanical and microstructural properties of recycling granite residual soil reinforced with glass fiber and liquid-modified polyvinyl alcohol polymer," Chemosphere, vol. 286, Article ID 131652, 2021.

[2] B. X. Yuan, Z. H Li, Z. Su, Q. Luo, M. Chen, and Z. Zhao, "Sensitivity of multistage fill slope based on finite element model," Advances in Civil Engineering, vol. 2021, Article ID 6622936, 13 pages, 2021.

[3] H. W. Ma, L. Liu, P. Wang, S. Yaun, Q-R. He, and X-L. Yang, "Calculation method and mechanism of ultimate side resistance of screw pile," Marine Georesources \& Geotechnology, vol. 2021, Article ID 2014003, 2021.

[4] M. S. Wang, D. X. He, and S. T. Tang, "New pile foundation technology of 21 Century: DX pile," Strategic Study of CAE, vol. 14, no. 1, pp. 4-12, 2012.

[5] M. X. Zhang, W. C. Cui, and P. Xu, "Comparative test research on squeezed branch piles and bored piles field," Journal of Henan Polytechnic University (Natural Science), vol. 36, no. 2, pp. 122-127, 2017.

[6] D. L. Qian, "Study on loading transfer law and FEM simulation of squeezed branch pile," Chinese Journal of Geotechnical Engineering, vol. 24, no. 3, pp. 371-375, 2002.

[7] F. Li, H. B. Song, and Y. D. Zhou, "Bearing behaviors of squeezed branch piles," Journal of Hohai University (Natural Sciences), vol. 38, no. 2, pp. 202-205, 2010.

[8] Y. Zhang, P. Chen, and Z. X. Zhao, "Experimental study on squeezed branch pile foundation in soft soil ground," Chinese Journal of Geotechnical Engineering, vol. 35, no. S2, pp. 994-997, 2013.

[9] M. X. Zhang, W. J. Cui, and P. Xu, "Research on soil displacement field around the squeezed branch pile under vertical load," Chinese Journal of Rock Mechanics and Engineering, vol. 36, no. 2, pp. 3569-3577, 2018.

[10] M. Zhang, P. Xu, W. Cui, and Y. Gao, "Bearing behavior and failure mechanism of squeezed branch piles," Journal of Rock Mechanics and Geotechnical Engineering, vol. 10, no. 5, pp. 935-946, 2018.

[11] X.-j. Gao, J.-c. Wang, and X.-r. Zhu, "Static load test and load transfer mechanism study of squeezed branch and plate pile in collapsible loess foundation," Journal of Zhejiang University Science, vol. 8, no. 7, pp. 1110-1117, 2007.

[12] Y. L. Wang, X. J. Li, and B. Q. Li, "Finite element numerical study on the axial bearing behaviors and factors of squeezed branch pile," China Civil Engineering Journal, vol. 48, no. 2, pp. 158-162, 2015.

[13] L. X. Li and X. J. Li, "Influence of squeezed branch pile bearing capacity on different numbers and positions of enlarged 
parts," Journal of Shandong University, vol. 46, no. 5, pp. 88-94, 2016.

[14] X. J. Gao and X. R. Zhu, "Forecasting ultimate bearing capacity of single squeezed branch pile by hyperbola method," Rock and Soil Mechanics, vol. 9, pp. 1596-1600, 2006.

[15] L. X. Li, X. J. Li, and B. Liu, "A simplified nonlinear settlement analysis method for axial loaded squeezed and branch piles," Chinese Journal of Underground Space and Engineering, vol. 14, no. 4, pp. 904-911, 2018.

[16] H. B. Seed and L. C. Reese, "The Action of Soft clay along Friction Piles," Transactions of the American Society of Civil Engineers, vol. 122, pp. 731-754, 1955.

[17] Z. X. Guo, Z. H. Yang, and J. S. Li, "Study on the bearing behaviours of large diameter cast-in-place pile," Geotechnical Investigation \& Surveying, no. 2, pp. 34-37, 2000.

[18] Ministry of Housing and Urban-Rural Development of the People's Republic of China, JGJ 171-2009 Design Specification for Cast-In-Place Piles with Expanded Branches and bells by 3way Extruding Arms, China Architecture \& Building Press, China, 2009.

[19] M. F. Randolph and C. P. Wroth, "An analysis of the vertical deformation of pile groups," Géotechnique, vol. 29, no. 4, pp. 423-439, 1979.

[20] N. Janbu, "Static bearing capacity of friction piles," in Proceedings of the European Conference on Soil Mechanics and Foundation Engineering, Wien, Austria, pp. 479-488, 1976.

[21] G. W. Clough and J. M. Duncan, "Finite element analysis of retaining wall behavior," Journal of the Soil Mechanics and Foundations Division, vol. 97, no. SM12, pp. 1657-1673, 1971.

[22] F. H. Kulhawy, "Behaviour of jacked and driven piles in sandy soil," Géotechnique, vol. 56, no. 4, pp. 245-259, 2006.

[23] J. Yang, L. G. Tham, P. K. K. Lee, S. T. Chan, and F. Yu, "Behaviour of jacked and driven piles in sandy soil," Géotechnique, vol. 56, no. 4, pp. 245-259, 2006.

[24] M. W. O'Neill and R. D. Raines, "Load transfer for pipe piles in highly pressured dense sand," Journal of Geotechnical Engineering, vol. 117, no. 8, pp. 1208-1226, 1991.

[25] X. Z. Liu and H. H. Zhu, "Experimental study on contact characteristics of typical soil layer and concrete in shanghai," Journal of Tongji University, vol. 5, pp. 601-606, 2004.

[26] R. Jardine, F. Chow, and R. Overy, ICP Design Methods for Driven Piles in Sands and Clays, Thomas Telford, London, UK, 2005.

[27] H. W. Ma, Y. Y. Wu, Y. Tong, and X. Q. Jiang, "Research on bearing theory of squeezed branch pile," Advances in Civil Engineering, vol. 2020, Article ID 6637261, 2020.

[28] B. Bai, G.-c. Yang, T. Li, and G.-s. Yang, "A thermodynamic constitutive model with temperature effect based on particle rearrangement for geomaterials," Mechanics of Materials, vol. 139, Article ID 103180, 2019.

[29] B. Bai, R. Zhou, G. Q. Cai, W. Hu, and G. C. Yang, "Coupled thermo-hydro-mechanical mechanism in view of the soil particle rearrangement of granular thermodynamics," Computers and Geotechnics, vol. 137, Article ID 104272, 2021.

[30] B. Bai, D. Rao, T. Chang, and Z. Guo, "A nonlinear attachment-detachment model with adsorption hysteresis for suspension-colloidal transport in porous media," Journal of Hydrology, vol. 578, Article ID 124080, 2019.

[31] B. Bai, Q. K. Nie, and Y. K. Zhang, "Cotransport of heavy metals and $\mathrm{SiO} 2$ particles at different temperatures by seepage," Journal of Hydrology, vol. 597, Article ID 125771, 2021.

[32] B. Yuan, Z. Li, Z. Zhao, H. Ni, Z. Su, and Z. Li, "Experimental study of displacement field of layered soils surrounding laterally loaded pile based on Transparent Soil," Journal of Soils and Sediments, vol. 21, no. 9, pp. 3072-3083, 2021.

[33] S. T. Tang, Research on Bearing Mechanism and Settlement of Single SD Pile and DX Pile Group, Beijing Jiaotong University, Beijing, China, 2012.

[34] M. Yang and X. H. Zhao, "An approach for single pile in layered soil," Journal of Tongji University, vol. 20, no. 4, pp. 421-428, 1992. 